\section{Call for Papers Issued for Oxford Conference on Microscopy of Semiconducting Materials}

The fifth in the series of biennial conferences on Microscopy of Semiconducting Materials is to be held at Oxford University, UK on April 6-8, 1987. Organized under the auspices of the Institute of Physics (UK) and cosponsored by the Materials Research Society and the Royal Microscopical Society, the conference will focus on the latest developments in the application of transmission and scanning electron microscopy to the study of the structural and electrical properties of semiconducting materials. Recent advances in the use of other microcharacterization techniques such as $x$-ray topography, field-ion microscopy, and ion backscattering spectrometry will also be featured. The materials of interest cover the complete range of elemental and compound semiconductors

The principal subject areas will include the properties of as-grown semiconductors, the behavior of lattice defects and impurities, the effects of processing treatments and the influence of structural defects on the electronic properties of materials and devices. Special conference sessions will concentrate on the properties of dislocations, high-resolution transmission electron

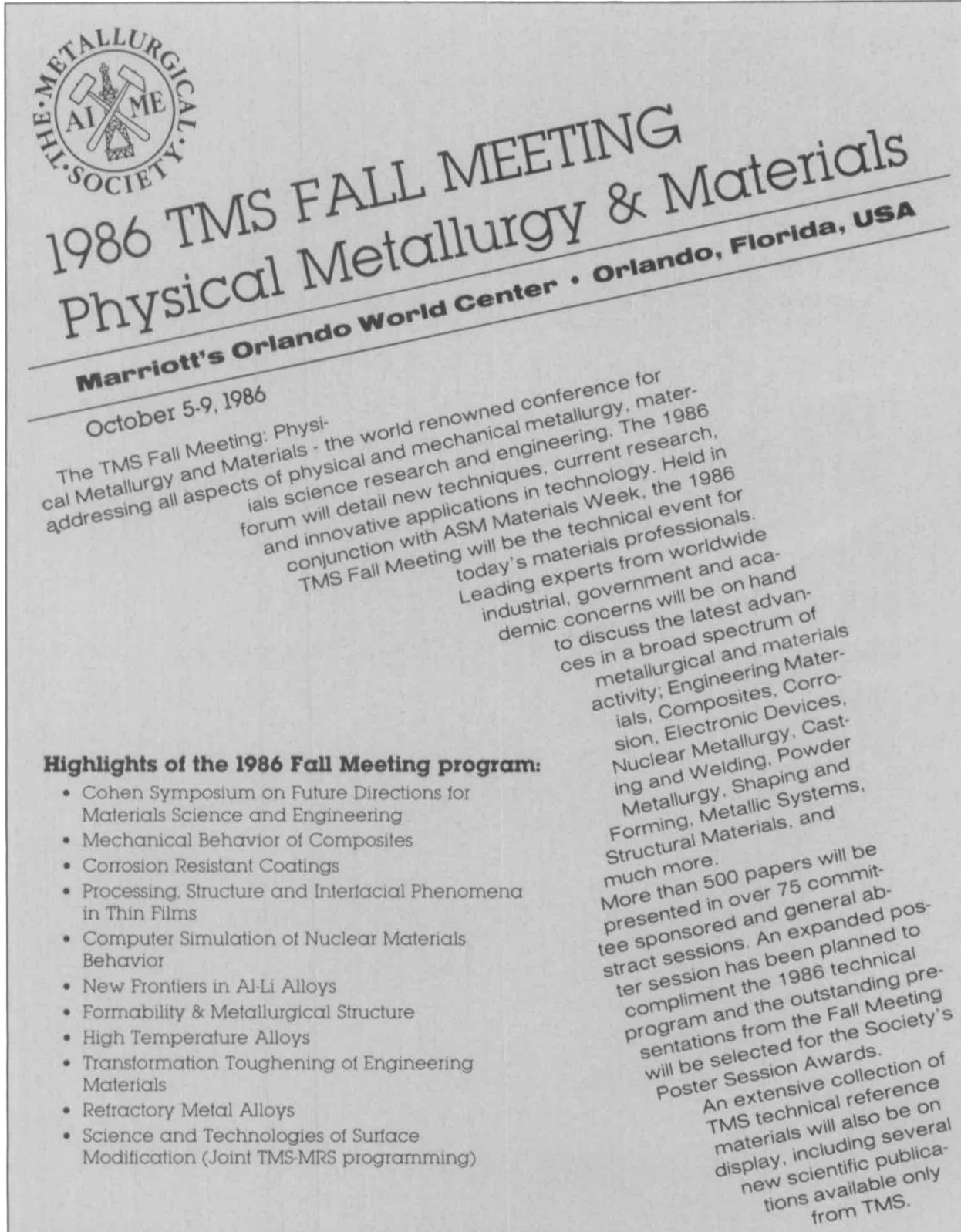

For complete information on the 1986 TMS Fall Meeting for Physical Metallurgy and Materials, in cluding technical highlights, housing and registration information, contact

microscope studies, epitaxial layer growth and superlattices, the effects of transient and conventional processing, semiconductor microanalysis, and elect ron beam testing of finished devices.

Invited speakers provisionally include $\mathrm{H}$. Alexander (Cologne University), "Dislocation Properties"; L.J. Balk (Duisburg University), "SEM Techniques"; W.J. Bartels (Philips, Eindhoven), "X-ray Studies of Superlattices"; A. Bourret (CEN, Grenoble), "Oxygen in Si"; C.B. Carter (Cornell University),"Compound Semiconductors"; J.L. Hutchison (Oxford University), "HREM of Interfaces"; M.H. Loretto (Birmingham University), "Semiconductor Microanalysis"; ]. Matsui (NEC, Kawasaki), "Dislocations in Bulk GaAs"; P.M. Petroff (University of Southern California-Santa Barbara), "Quantum Well Wire and Boxes."

Contributed papers are requested in all the areas outlined above and the conference proceedings will be published. Further information about abstract submission (deadline December 1, 1986) and registration can be obtained from the conference Co-Chairmen, A.G. Cullis, Royal Signals and Radar Establishment, St. Andrews Road, Malvern, Worcs, WR14 3PS, UK (telephone: UK-6845-2733 ext. 2509) and P.D. Augustus, Plessey Research Ltd., Caswell, Towcester, Northants. NN12 8EQ, UK (telephone: UK-327-50581).

\section{Surface Modification To Be Explored at 1986 TMS Fall Meeting}

The Materials Research Society will cosponsor two technical sessions at the 1986 Fall Meeting of The Metallurgical Societ y (TMS) in Orlando, Florida, October 5-9. The sessions entitled "Surface Modification: Review Update and Tutorial" are being organized by Ram Kossowsky of Penn State's Applied Research Laboratory in collaboration with Anthony Giamei of United Technologies and Paul S. Peercy of Sandia National Laboratories.

Surface modification of materials is a broad subject that has been attracting an increasing amount of attention from both the basic science research and the engineering applications comm unities. The potential of surface modification is derived from the concept analogous to coatings and composite materials. It provides for the optimization of the specific properties of the surfaces of materials related to their functions and to their interactions with the environment, while keeping bulk properties unaffected

The list of applications for surface modified materials is growing. To name a few: hard coatings for wear resistance, precision toolings, thermal barriers, hightemperature corrosion protection, oxida- 
tion resistance, electronic devices, biocompatible materials, and devices for surgical implants, etc.

In the morning session, G.A. Somorjai of Berkeley will discuss advances in characterization of surface atomic structures Modern surface science makes it possible to examine structural response to chemical stimulus in coatings application, lubrication and catalysis. D.M. Mattox of Sandia National Laboratories will talk about coatings/substrate adhesion. Factors affecting the adhesion phenomenon include surface chemistry, contact area, interfacial reactions, substrate-film physical properties and degradation mechanisms. The remainder of the first session papers will address surface modification processes.

C.J. McHargue of Oak Ridge National Laboratory will examine the physical processes associated with ion implantation and ion beam mixing and the structures they produce in metals and ceramics. M.H. Jacobs of Ipsen Industries International will review the industrial status of plasma carburizing and plasma nitriding. In addition to examples of metallurgical structures and property improvements, his paper also details integration of these plasma processes in to flexible manufacturing cells.

E.N. Kaufmann of Lawrence Livermore National Laboratory will report on metastable phase formation and surface modification produced by rapid beam-melting of alloy surfaces, and J. Narayan of North Carolina State University will review developments in transient thermal processing of semiconductors.

In the afternoon session, a nother plasma process-plasma polymerization-will be discussed by H.K. Yasuda of the University of Missouri-Rolla. This process creates exotic new materials, which can effectively modify conventional polymer surfaces. J.A. Thornton of the University of IllinoisUrbana will address sputtering methodology for deposition of metals, insulators and semiconductors. Thornton relates inherent characteristics of the sputtering technique to microstructure and electrical properties of deposits. In a nother processdescriptive presentation, C. Bergman of Metal-Arc will summarize results of arc vapor ion deposition of refractory metals. This technique has developed quickly for the growth of corrosion and wear-resistant TiN coatings on industrial tooling. A.W. Mullendore of Sandia will review deposit morphology, substrate interactions, epitaxy and residual stress effects associated with chemical vapor deposition. A specific surface behavior review paper by $\mathrm{H}$. Yoon and W.B. Carter of Georgia Institute of Technology will examine the effect of film composition on corrosion behavior of ionplated TiC. Similarly, D.A. Hardwick of Los Alamos National Laboratory will present a study on the influence of surface preparation on tritium permeation into $304 \mathrm{~L}$ stainless steel.

These sessions jointly programmed by TMS and MRS will provide the Fall Meeting attendees with the most complete information available in areas of interest to members of both organizations.

TMS will cosponsor the symposium, Multicomponent Ultrafine Microstructures, at the 1986 MRS Fall Meeting, December 1-6, Boston, MA. See further information on this program in the next issue of the BULLETIN.

\section{Workshop on Tungsten and Other Refractory Metals for VLSI Applications}

The Workshop on Tungsten and Other Refractory Metals for VLSI Applications will be held November 12-14, 1986 at the Xerox Palo Alto Research Center (PARC) in Palo Alto, CA. This workshop is the third in a series organized to bring together active researchers in refractory metals for advanved IC applications. The first two workshops, cosponsored by Sandia National Laboratories, emphasized numerous advances in selectively deposited tungsten films. Participation in the workshop series has been very strong, and its purview now extends to other refractory metals in addition to tungsten.

The 1986 worksh op will consist of singlesession presentations containing both contributed and invited papers, supplemented by informal panel discussions. MRS will publish the complete proceedings in early 1987.

Proceedings from the first two workshops have already been published in a single volume by MRS.

A partial list of topics includes: LPCVD techniques, deposition kinetics, CVD gas chemistry, film properties (physical, chemical, electrical), film substrate interaction, refractory metal interconnects, intermetal contact plugs, diffusion barriers, new device structures, adhesion of blanket tungsten to oxides, and etching of tungsten and refractory metals. Paneldiscussion topics include: selectivity determinants, deposition equipment (design, evaluation, strengths, weaknesses), reliability of devices with tungsten elements, and future trends (the role of refractory metals in VLSI).

For information, contact Continuing Education in Engineering, University Extension, University of California, 2223 Fulton Street, Berkeley, CA 94720; telephone (415) 642-4.151.
New from the Materials Research Society

\section{Tungsten and Other Refractory Metals for VLSI Applications}

\author{
Edited by R. S. Blewer, Sandia National Laboratories
}

\section{Covering more than $75 \%$ of the research published on LPCVD tungsten in the past five years.}

This new proceedings volume contains 59 papers that comprised both the 1984 and 1985 Workshops on Tungsten and Other Refractory Metals for VLSI Applications, sponsored by Sandia National Laboratories and the University of California-Berkeley's University Engineering Extension. Tungsten's self-aligning characteristics when applied by low-pressure chemical vapor deposition (LPCVD) and its high electrical conductivity make it ideal for use in advanced microcircuits and in source flash drain covers, via fills and low-resistance shunts on polysilicon lines.

A valuable source book imperative for anyone presently involved in or starting up research in the field of LPCVD.

MRS Members - \$34 U.S. Nonmembers - \$39 Foreign Nonmembers - \$45

Prepayment Required.

Send to: Materials Research Society, Publications Department, 9800 McKnight Road, Suite 327, Pittsburgh, PA 15237;

telephone (412) 367-3012. 